\title{
Patient Tracking in a Multi-Building, Tunnel-Connected Hospital Complex
}

\begin{tabular}{|r|l|}
\hline Journal: & IEEE Sensors Journal \\
\hline Manuscript ID & Sensors-33176-2020 \\
\hline Manuscript Type: & Regular Paper \\
\hline Duthor: & 23-Mabmitted by the 20 \\
\hline Complete List of Authors: & $\begin{array}{l}\text { Trigo, Jesus Daniel; Universidad Publica de Navarra, EEC } \\
\text { Klaina, Hicham; Universidad de Vigo, Dept. of Teoría de la Señal y } \\
\text { comunicación, University of Vigo, 36310 Vigo, Spain } \\
\text { Picallo, Imanol; Universidad Publica de Navarra, EEC } \\
\text { Lopez-Iturri, Peio; EE } \\
\text { Alejos, Ana Vázquez; Universidad de Vigo, Teoria de la Señal } \\
\text { Astráin, José Javier; Public University of Navarra, Mathematical } \\
\text { Engineering and Computer Science } \\
\text { Falcone, Francisco; EE } \\
\text { Serrano, Luis; Public University of Navarra, EEC }\end{array}$ \\
\hline Keywords: & \begin{tabular}{l} 
APPL \\
\hline
\end{tabular} \\
\hline
\end{tabular}



or future media, including reprinting/republishing this material for advertising or promotional purposes, creating new collective works, for resale or redistribution to servers or lists, or reuse of any copyrighted component of this work in other work.

\title{
Patient Tracking in a Multi-Building, Tunnel-Connected Hospital Complex
}

\author{
Jesús D. Trigo, Hicham Klaina, Imanol Picallo, Peio Lopez-Iturri, José Javier Astrain, Ana Vazquez \\ Alejos, Francisco Falcone, Senior Member, IEEE, and Luis Serrano-Arriezu, Senior Member, IEEE
}

\begin{abstract}
Patients admitted to Intensive Care Units (ICU) are transported from and to other units. Knowing their location is strategic for a sound planning of intra-hospital transports as well as resources management. This is even more crucial in big hospital complexes, comprised of several buildings often connected through tunnels. In this work, a patient tracking application in a multi-building, tunnel-connected hospital complex (the Hospital Complex of Navarre) is presented. The system leverages Internet of Medical Things (IoMT) communication technologies, such as Long Range Wide-Area Network (LoRaWAN) and Near Field Communication (NFC). The locations of the LoRaWAN nodes were selected based on several factors, including the situation of the tunnels, buildings services and medical equipment and a literature review on intrahospital ICU patients' trips. The possible locations of the LoRaWAN gateways were selected based on 3D Ray Launching Simulations, in order to obtain accurate characterization. Once the locations were set, a LoRaWAN radio coverage studio was performed. The main conclusion drawn is that just one LoRaWAN gateway would be enough to cover all overground LoRaWAN nodes deployed. A second one would be required for underground coverage. In addition, a remote, private cloud infrastructure together with a mobile application was created to manage the information generated. On-field tests were performed to assess the technical feasibility of the system. The application provides with on-demand ICU patients' movement flow around the complex. Although designed for the ICU-admitted patients' context, the system could be easily extrapolated to other use cases.
\end{abstract}

Index Terms - Internet of Medical Things (IoMT), Wireless Sensor Networks (WSNs), LoRaWAN, 3D Ray Launching

This work was supported by project "Arquitectura "Internet of Medical Things" (IoMT) para la monitorización y gestión semántica de datos relativos a enfermedades cardiovasculares" (Ref: PJUPNA29) funded by the Universidad Pública de Navarra and the research projects TEC2017-85529-C03-3R and RTI2018-095499-B-C31, funded by Ministerio de Ciencia, Innovación y Universidades, Gobierno de España (MCIU/AEI/FEDER,UE), as well as from European Union's Horizon 2020 research and Innovation programme under grant agreement $\mathrm{N}^{\circ}$ 774094 (Stardust-Holistic and Integrated Urban Model for Smart Cities).

J.D. Trigo, I. Picallo, P. Lopez-Iturri, F. Falcone and L. SerranoArriezu are with the Department of Electrical, Electronic and Communication Engineering and with the Institute of Smart Cities, Public University of Navarre, Pamplona, 31006 Navarra, Spain (e-mail: \{jesusdaniel.trigo, imanol.picallo, peio.lopez, francisco.falcone, lserrano\}@unavarra.es).

H. Klaina, A. V. Alejos are with the Department of Teoría de la Señal y Comunicación, University of Vigo, Pontevedra, Vigo, Spain, e-mail: \{hklaina, analejos\}@uvigo.es,

J.J. Astrain is with the Department of Statistics, Computer Science and Mathematics and with the Institute of Smart Cities, Public University of Navarre,31006 Pamplona, Navarra, Spain (e-mail: josej.astrain@unavarra.es).

\section{INTRODUCTION}

$\mathrm{O}$ VER the last years, the Internet of Things (IoT) concept has steadily gained momentum. Since IoT is essentially a network of technologically interconnected physical/virtual things to provide services [1], the fields of application range widely, including governance, automation, location, defense, logistics, and smart cities, among others [2]. Nevertheless, one of the most challenging and promising fields is the medical and health care sector, where IoT and medicine converge to conceive a new paradigm, usually referred to as the Internet of Medical Things (IoMT) [3,4]. In the future, IoMT is expected to expand through the $5 \mathrm{G}$ network, allowing significant enhancements on latency, efficiency and reliability, among others; fundamental requirements for smart healthcare applications [5].

Services and applications encompassed by the term IoMT cover a wide spectrum, including telemetry and monitoring of vital signs [6-8], ambient assisted living [9,10], context-aware healthcare systems [11], wearable medical device management, authentication/identification $[12,13]$, or location and tracking of medical equipment, assets or patients $[14,15]$.

Focusing on the latter use case, hospitalized patients may be transferred from one unit to another, depending on their medical requirements. For example, patients with threatened or established organ failure are admitted to Intensive Care Units (ICU) [16]. Even though their situation is critical, they suffer from potentially recoverable conditions. When the lifethreatening situation is reverted, they are discharged from the ICU and referred to another unit. Besides transports due to admission or discharge, ICU patients typically require round trips to other units for diagnostic or therapeutic reasons [17]. Thus, knowing their location is key for a sound planning of the transports, efficient coordination between units and, ultimately, safer healthcare [18]. Naturally, this is even more crucial at large hospital complexes, covering wide areas and consisting of several buildings. Moreover, the buildings of such hospital complexes may be connected via underground tunnels, in order to enable intra-hospital transport of patients.

Technologically, the use of sensors in combination with communications technologies to create IoMT-enabled, patient tracking applications have been described in the literature [19]. Table I summarizes the research works related to location and tracking of medical equipment, assets or patients in smart healthcare environments. 
TABLE I

RELATED WORK

\begin{tabular}{ll}
\hline \hline References & Authors contributions \\
\hline
\end{tabular}

[20] In this contribution, a system that controls the material and human resources of an ICU has been presented. It uses Infrared (IR) technology, which detects the presence of the tags that manage the entry and departure of the patients and healthcare professionals.

[21] This paper presents Laura system (Localization and Ubiquitous Monitoring of Patients for Health Care Support), which performs localization, tracking and monitoring of patients hosted at nursing institutes by exploiting a wireless sensor network based on the IEEE 801.15.4 and IEEE 802.11 standards.

[11] In this paper, a novel IoT-aware smart hospital system for monitoring and tracking of patients, workers and medical devices is presented. It describes a complex architecture to allow interoperation among WSN, Radio Frequency Identification (RFID) and smart mobile technologies.

[22] This paper presents LOBIN platform, which allows location and biomonitoring through WSN within hospital environments The location algorithm is based on the communication of etextile smart shirt wearable and infrastructure end devices within an 802.15.4 network. The system has tested in a $300 \mathrm{~m}^{2}$ scenario in the Cardiology Unit of La Paz Hospital, Madrid (Spain).

[23] This paper presents a Wireless Body Area Network (WBAN) communication within a network of WBANs in a hospital buildings simulated scenario using WiFi technology. The simulation analyzes the internal wall loss, the packet loss rate and node to access-point delay, among others.

[24] This paper has developed a novel training free-device freelocalization using commercial WiFi devices. Thus, it estimates the target location without using any new equipment. So that, it analyzes the WiFi channel state information and uses a particle filter algorithm to estimate the location.

[25] This paper presents empirical radiofrequency results for an experimental measurement campaign for WBAN in a $61 \mathrm{~m}^{2}$ scenario within a hospital. It analyzes the results of UWB and four narrow-band frequencies in order to find a suitable body location, comparing both power links.

[26] In this work, Ultra Wide Band (UWB) technology is used for localization and tracking of human body and limbs movement, due to it is high accuracy. For that purpose, UWB channel characterization has been performed in a small area with a human body surrounded by UWB antennas.

[27] This contribution presents an architecture for patients and professional healthcare tracking. For that purpose, it proposes Bluetooth Low Energy (BLE) tags and beacons deployment within a hospital.

This work This paper presents a patient tracking system application based on IoMT communication paradigm using short-range (NFC) and long-range (LoraWAN) wireless technologies, in a $112000 \mathrm{~m}^{2}$ multi-building and tunnel-connected hospital complex. Furthermore, an in-house developed 3D Ray Launching algorithm is used to estimate LoRaWAN gateways location. Finally, a remote and private cloud infrastructure along with a mobile application is presented monitoring patients' movement flow within the hospital complex.

Among the existing and emerging communication technologies and standards that enable IoT-based healthcare applications [28], the group referred to as Low Power Wide Area Networks (LPWAN) has become prevalent mainly because of their valuable characteristics: low cost, low power and long-range [29]. There are several proprietary and standardized LPWAN technologies available, being SigFox, LoRaWAN, and Narrow Band (NB)-IoT [30] the most relevant for large-scale IoT deployment. A recent comparative study between those three LPWAN technologies showed that SigFox and LoRaWAN are advantageous in terms of battery lifetime, capacity, and cost, while NB-IoT offers benefits in terms of latency and quality of service [31]. SigFox offers better range than LoRaWAN (10 km vs. $5 \mathrm{~km}$ in urban environments) but, unlike SigFox, LoRaWAN offers basic encryption (Advanced Encryption Standard (AES), 128 bits), the possibility of private networks, a topology of star of stars and even the possibility of positioning by means of the Time Difference Of Arrival (TDOA) technique. However, such technique would increase the cost since it would require the use of a few more gateways acting as anchors with high time accuracy. Without TDOA, performing accurate indoor positioning using the received power alone has been described as not satisfactory even with hundreds of nodes [32]. Moreover, the use of TDOA exhibits limitations in terms of synchronization requirements at the receiver side and is also influenced by non-line of sight conditions, multipath propagation and interference [33]. Recently, a LoRaWANbased tracking system for patients with mental disorder has been designed [34] and tested at a campus and a shopping mall [35]. It consisted of a tracking device on the patient side, which collected the Global Positioning System (GPS) coordinates and sent them to a server through the LoRaWAN architecture. This approach, although functional, increases cost and energy consumption.

In this work, an IoMT-enabled, patient tracking application in a multi-building, tunnel-connected hospital complex is presented. Due to the reasons stated above, short-range and long-range wireless technologies (more specifically, Near Field Communication (NFC) and LoRaWAN) have been selected as enablers. The approach was tested in a real scenario, the ICU-admitted patients of the Hospital Complex of Navarra (HCN). The aim is twofold: first, determine where and how many LoRaWAN nodes and gateways would be required in this case scenario to provide with adequate radio coverage in a patient-tracking application, and, second, design and develop such application. Complete volumetric analysis of wireless channel conditions have been obtained in order to perform coverage/capacity analysis of the proposed system, considering indoor/outdoor conditions in the hospital complex. Moreover, real system validation has been performed following a holistic approach.

The rest of the paper is organized as follows: Section II presents the scenario under test, including overground and underground maps, internal organizations, equipment and tasks performed in each building, and intra-hospital transport circuits for ICU patients. This section also presents the materials and methods used to carry out the project. The results are shown in Section III. More specifically, section III.A presents the LoRaWAN Nodes locations selection, 3D Ray Launching simulations analysis for gateways locations selection, as well as the presentation of the measurements results, in terms of received packets, Received Signal Strength Indicator (RSSI) and Signal-to-Noise Ratio (SNR) at the LoRaWAN gateways from the different LoRaWAN nodes. The application is illustrated in Section III.B, including the 
main interface, the patient location map, the software architecture, as well as the cloud infrastructure. Discussion and conclusions are drawn in Section IV.

\section{MATERIAL AND METHODS}

\section{A. Scenario under Test}

The HCN is the largest tertiary referral hospital in Navarra, an Autonomous Community in Spain, populated by approximately 650000 inhabitants. The complex is comprised of 27 buildings, covering an area of roughly $200000 \mathrm{~m}^{2}$ (equivalent to nearly 50 acres). There are more than 1000 beds distributed in two major buildings (referred to as $\mathrm{H}$ and $\mathrm{HVC}$ ), which in turn are comprised of a number of pavilions. A general view of the hospital complex with buildings names is shown in Fig. 1.
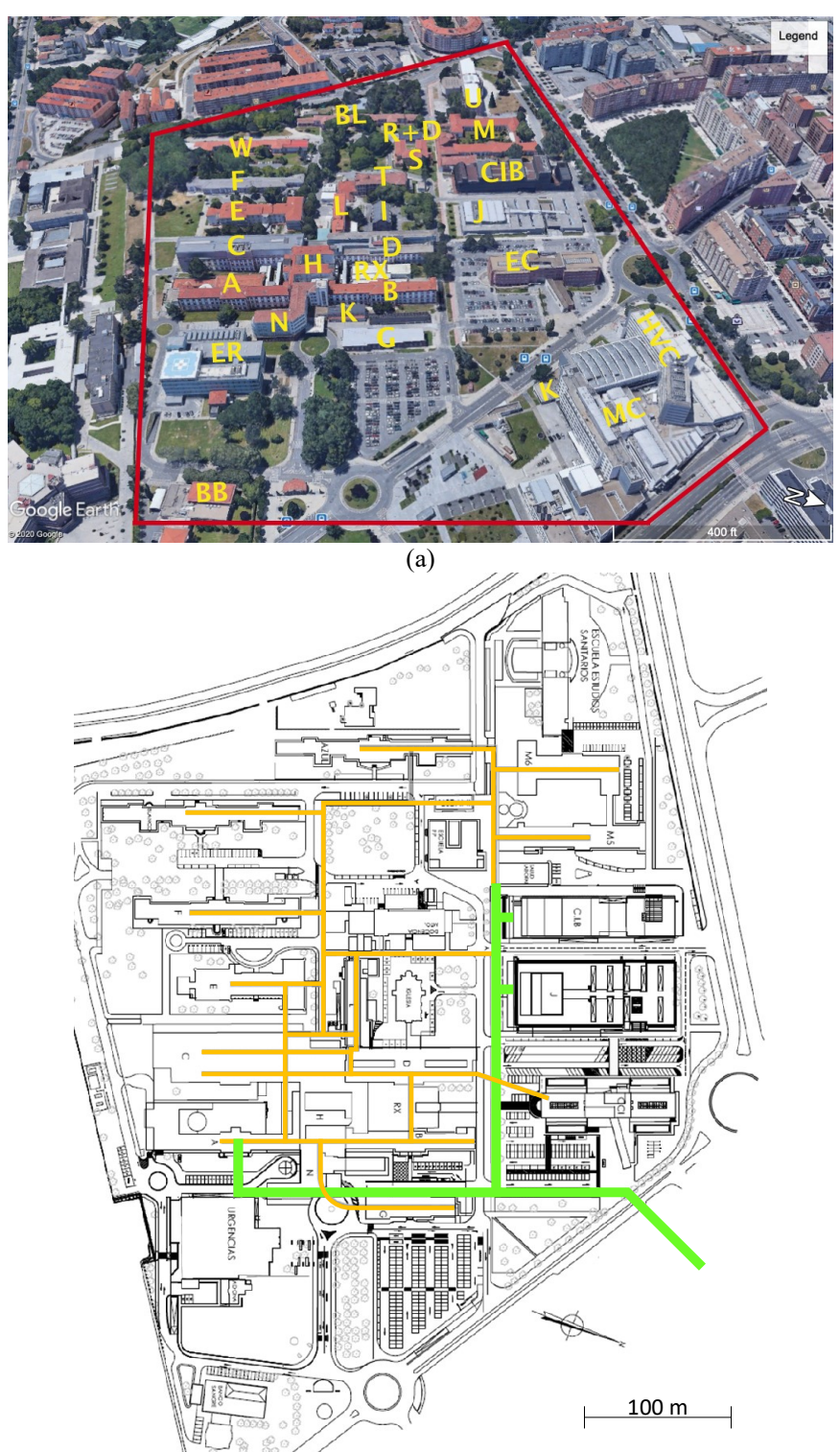

(b)

Fig. 1. (a) Google Earth's view of the buildings of the HCN. (b) Schematic tunnel network connecting the buildings at the HCN.
As can be seen in Fig. 1a, some buildings are directly connected. Nonetheless, most of them are connected through underground tunnels. In Fig. 1b, the tunnel network connecting the buildings at the HCN is shown. Main tunnels (which are wider and connect the core buildings of the complex) are depicted in green, while subordinate tunnels (which are narrower and connect secondary buildings) are painted in orange. Because of that, gurneys are usually driven through green tunnels.

Table II enumerates the main buildings, and pavilions, as well as the units or services inside them. The large medical devices and equipment is distributed all over the complex, but it is mainly set in the following buildings:

- RX: 2 Computed Tomography (CT) scans, 1 Magnetic Resonance Imaging (MRI), 2 mammography and angiography devices, and $2 \mathrm{x}$-ray rooms.

- ER: 1 CT scan, a digital portable x-ray device and 2 fully equipped digital image rooms.

- J: 2 CT scans and digital echographers.

- C (where the ICU is located): endoscopy and angiography devices.

- HVC: 2 CT scans, MRI, mammography, angiography, endoscopy, orthopantomography. C-arm x-ray and fluoroscopy, and 2 fully equipped digital image rooms.

TABLE II

BUILDINGS AT HCN AND THE UNITS OR SERVICES INSIDE THEM

\begin{tabular}{|c|c|c|c|}
\hline Name & Units / Services & Name & Units / Services \\
\hline $\mathrm{HVC}$ & $\begin{array}{l}\text { General Ward } \\
\text { Hospitalization (general) } \\
\text { Surgery } \\
\text { Ob-gyn } \\
\text { Genetics } \\
\text { Neurophysiology }\end{array}$ & B & $\begin{array}{l}\text { Day hospital } \\
\text { Pain management unit } \\
\text { Neurophysiology } \\
\text { Urology } \\
\text { Post-anesthetic recovery } \\
\text { Nuclear medicine } \\
\text { Consultations }\end{array}$ \\
\hline $\mathrm{H}$ & $\begin{array}{l}\text { General Ward } \\
\text { Hospitalization (surgery) } \\
\text { Hospitalization (internal) } \\
\text { Operating room }\end{array}$ & $\mathrm{MC}$ & $\begin{array}{l}\text { Maternity and children } \\
\text { Pediatrics } \\
\text { Pediatric ICU } \\
\text { Neonatology }\end{array}$ \\
\hline $\mathrm{C}$ & $\begin{array}{l}\text { ICU } \\
\text { Hospitalization (hematology) } \\
\text { Hospitalization (oncology) } \\
\text { Day hospital } \\
\text { Oncology } \\
\text { Endoscopies }\end{array}$ & $\mathrm{D}$ & $\begin{array}{l}\text { Hospitalization (cardiac) } \\
\text { Hospitalization (digestive) } \\
\text { Coronary unit } \\
\text { Hemodynamics } \\
\text { Cardiology }\end{array}$ \\
\hline M & $\begin{array}{l}\text { Psychiatry } \\
\text { Occupational health } \\
\text { Occupational hazard } \\
\text { Women's service center }\end{array}$ & E & $\begin{array}{l}\text { Infectious diseases } \\
\text { Ictus } \\
\text { Geriatrics } \\
\text { Psychiatry }\end{array}$ \\
\hline ER & $\begin{array}{l}\text { Emergency } \\
\text { Observation Room } \\
\text { Heliport }\end{array}$ & $\mathrm{J}$ & $\begin{array}{l}\text { Oncology } \\
\text { Radiotherapy } \\
\text { Nephrology }\end{array}$ \\
\hline $\mathrm{N}$ & $\begin{array}{l}\text { Operating room } \\
\text { Hospitalization (surgery) } \\
\text { Hospitalization (internal) }\end{array}$ & W & $\begin{array}{l}\text { Substance dependence } \\
\text { Day hospital (psychiatry) }\end{array}$ \\
\hline $\mathrm{L}$ & $\begin{array}{l}\text { Microbiology } \\
\text { Pharmacy }\end{array}$ & CIB & $\begin{array}{l}\text { Research Institute } \\
\text { Laboratory }\end{array}$ \\
\hline $\mathrm{RX}$ & Radiology & A & Hematology \\
\hline $\mathrm{F}$ & Pathological anatomy & $\mathrm{U}$ & University \\
\hline $\mathrm{EC}$ & External consultations & G & Management \\
\hline $\mathrm{BB}$ & Blood Bank & $\mathrm{T}$ & Teaching \\
\hline $\mathrm{R}+\mathrm{D}$ & Research & $\mathrm{S}$ & School \\
\hline $\mathrm{I}$ & Church & $\mathrm{K}$ & Cafeteria \\
\hline $\mathrm{BL}$ & Administration & & \\
\hline
\end{tabular}




\section{B. Materials}

The LoRaWAN technology is a suitable solution for wireless communication in such a huge space as the hospital complex, offering a very low sensitivity until $-148 \mathrm{dBm}$. In these measurements, a Seeed NFC Shield V2.0 (which offers a reading range of $10 \mathrm{~cm}$ ) connected to a The Things Uno (TTN Uno) LoRaWAN module has been employed. This LoRaWAN module consists of an ISM $868 \mathrm{MHz}$ Microchip RN2483 based on Arduino Leonardo, and will be in charge of sending packets to the TTN gateway. The transmitted power was $14 \mathrm{dBm}$ with an omnidirectional antenna. The received packets by the TTN gateway are encoded with the Cayenne Low Power Payload (Cayenne LPP) to be displayed in the Cayenne dashboard, which is a ready to use platform for IoT projects, for storage and display, which is a ready to use platform for IoT projects, for storage and display. The tracking device is an Adafruit Classic $1 \mathrm{~K}$ bracelet. All these steps are presented in Fig. 2.

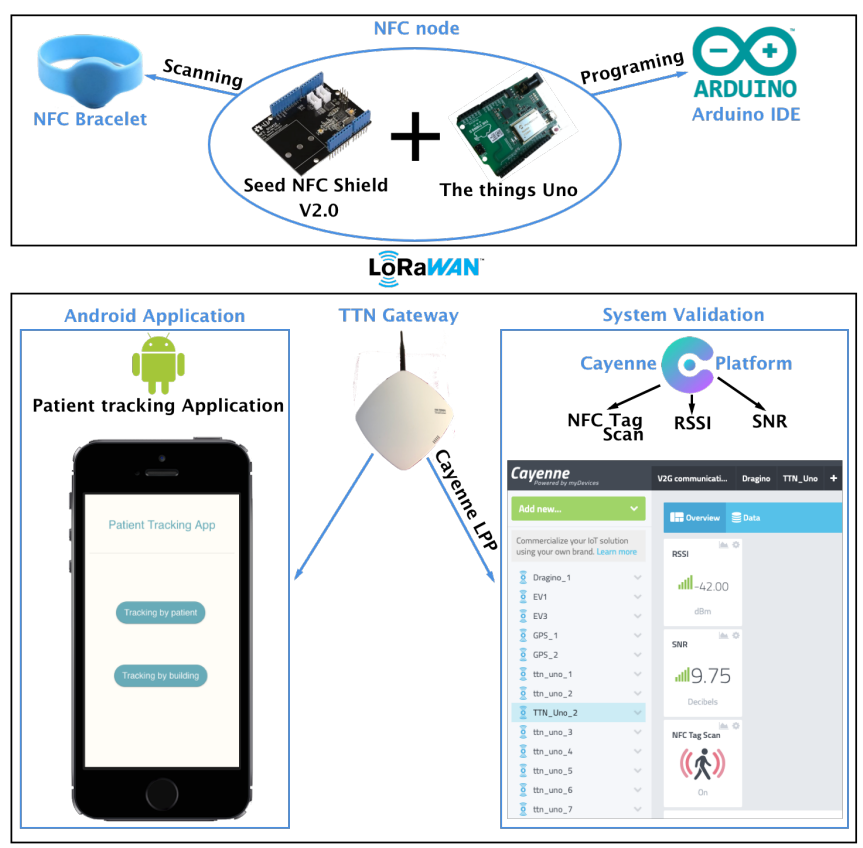

Fig. 2. Schematic description of the system validation steps and application.

To guarantee adequate protection and custody of data, the information system developed has been implemented on a private cloud infrastructure. Specifically, an infrastructure based on Apache CloudStack has been implemented with its own uninterruptible power supply (UPS), a redundant storage system on a solid state RAID 5 disk array (SSD), computer computational equipment, NVidia Quadro RTX GPUs and network electronics. The infrastructure is completely virtualized, both at the hardware level using Canonical MaaS (metal as a Service), and at the software level using VMware ESXI and VMware vSphere with Linux Ubuntu. This configuration allows an agile and comfortable reconfiguration of the infrastructure on demand, both at the hardware level (computing, storage and network) and at the level of the operating system, virtual machines and containers. Having to work with personal health data referring to patients and health personnel, it has been decided to use Temporary User Identities (TUIs). International data protection regulations, such as the General Data Protection Regulation (GDPR), urge that this data be protected with the highest level of security. . To avoid complicating the system with complex encryption mechanisms, a temporary identification mechanism is employed that automatically renews itself each time the user's device returns to the ICU Therefore, although the information regarding the location of each user is kept at all times, the system keeps the individual's real identity and TUI always completely dissociated. With this aim, a dynamic temporal identity assignment service is available that provides the location system with temporary identifiers, while storing in a separate system the link between these TUIs and the real individuals. Thus, the monitoring tool can know the aggregate movement flows, it can discriminate by type of user (patient, specialist, caretaker ...) or by displacement pattern, but it cannot directly know their identity. If necessary, the system could, with the corresponding authorization, cross both information and uniquely identify the user. Currently, work is being done under the framework of informed consent. The patient is warned that his/her movements will be tracked. It should be remembered that while a patient is in the ICU, his/her safety is the responsibility of the hospital. When it is not possible to obtain the patient's informed consent beforehand, the patient's relatives are informed as soon as possible. In the case of employees, they sign the informed consent when they sign the contract to join the hospital.

\section{Methods}

Initially, the locations of the LoRaWAN nodes were chosen. The decision was based on several factors: (a) the type of patients to be monitored (ICU patients), (b) the services they are admitted from or discharged to, (c) the units they make round trips to, (d) the layout of the buildings on the map (see Fig. 1a), (e) the route the patients would make (over and underground) to travel from those destinations to the ICU or back (see Fig. 1b), and (f) the medical equipment available in the different buildings (see Section II.A). Points (b) and (c) required a literature review, whose results are described below in Section III.A.1. Second, several positions for the LoRaWAN gateways were chosen to measure the actual radio coverage. In order to select the optimal gateway locations, inhouse 3D Ray launching simulations of the HCN scenario for wireless channel analysis in order to obtain coverage/capacity distributions were carried out (Section III.A.2). Third, the LoRaWAN nodes were deployed at the selected points, turned on and configured to send packets every 30 s to the LoRaWAN gateway. Moreover, the LoRaWAN gateway at our disposal was moved around the locations selected in step 2. The RSSI, SNR and the received packets at each location were recorded and stored for further analysis (see Section III.A.3). Based on the results of this step, the final position of the gateway(s) was chosen (see Section III.A.3). Finally, once the location of the gateway(s) was set, the patient tracking application was designed and developed (see Section III.B). On-field tests with NFC-enabled bracelets were performed with volunteers. 


\section{RESULTS}

\section{A. Location of Devices and Radio Coverage Measurements}

1) Location of LoRaWAN Nodes

ICU patients are one example of the need of hospital transport, either at admission, discharge or for round trips to other units. In a multi-centric (307 ICUs), international (35 countries from all continents) study with a cohort of almost 20000 ICU patients, the sources and destinations of critically ill patients were analyzed [35]. In order to illustrate the transfer of patients, the tables with the data presented in [35], have been repurposed here as Fig. 3.

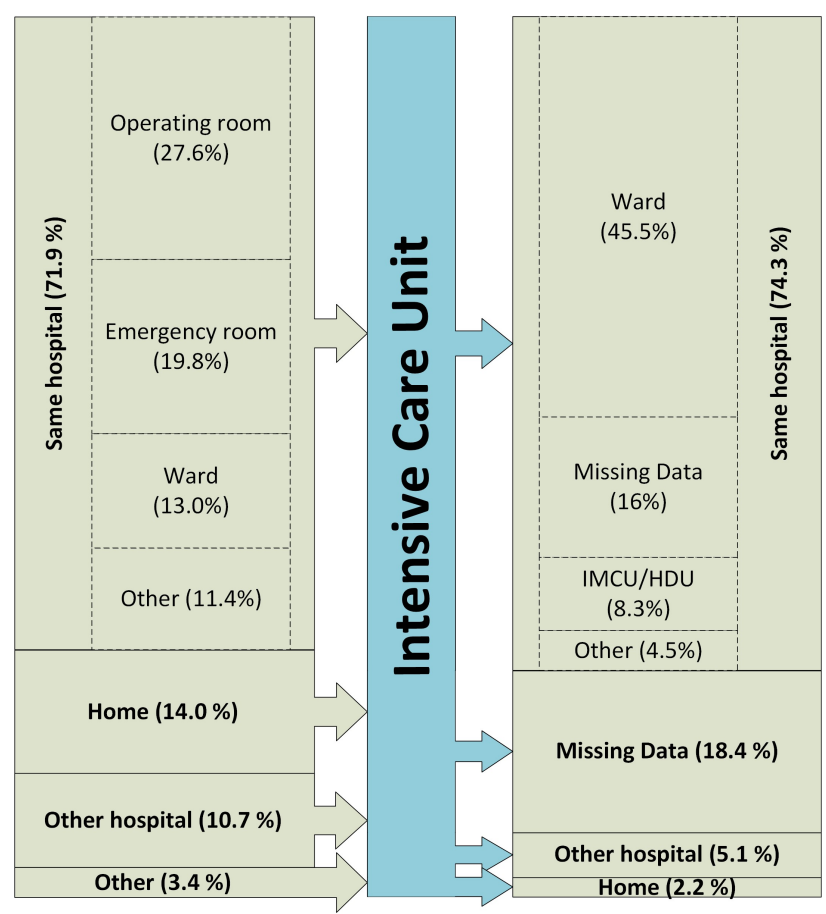

Fig. 3. Source and destination of ICU patients. Data extracted from [35].

As it can be seen, the source of admission to the intensive medicine service is usually the same hospital (71.9\%), being the Operating Room (OR, 27.6\%), the Emergency Room (ER, 19.8\%), and the general ward (13.0\%, due to complication of acute illnesses) the most prominent. Other important origin places are the patient's home (14\%) and other hospitals (10.7\%). At discharge, the majority of the ICU patients stay at the same hospital (74.3\%). Most patients are transferred back to the general ward $(45.5 \%)$, although a considerable percentage $(8.3 \%)$ are transferred to a Intermediate Care Unit or the High Dependency Unit (ICU/HDU), where they can remain under close observation.

As stated before, ICU patients require round trips to other units, either for diagnosis or therapy [17]. For instance, ICU patients might need an image-based test (e.g. a MRI procedure), or a radiation session (as therapy). In a study with more than 1000 ICU patients, the round trips of critically ill patients from the ICU to an intra-hospital destination and back to the ICU were analyzed [36]. The results showed that $44 \%$ of ICU-admitted patients required at least one round trip to other units $(45 \%$ of those, two or more transports). Considering all transports $(n=800), 55 \%$ of them were to the CT scan, $16 \%$ to interventional radiology, $15 \%$ to the OR, $4 \%$ to the MRI, $4 \%$ to radiation therapy and the remaining $6 \%$ to other locations, such as the positron emission tomography, general radiology or nuclear medicine.

Based on the evidence described above, eight locations were selected for the LoRaWAN nodes, six of them overground and two underground (' $x$ ' marks in Fig. 4), including:

- the ICU at building $\mathrm{C}$,

- the OR at building $\mathrm{H}$,

- the ER building (ER and observation room),

- the general ward $(\mathrm{GW})$ at building HVC (note there is another general ward at building $\mathrm{H}$, but that building was already covered with another node, and also building HVC was farther from the rest of locations, and thus subject to a worse radio coverage),

- the RX building,

- the radiotherapy service at building $\mathrm{J}$,

- the north-to-south main tunnel (T2) at the intersection with the other main tunnel, and

- the east-to-west main tunnel (T1) by building EC (intersection with secondary tunnel).

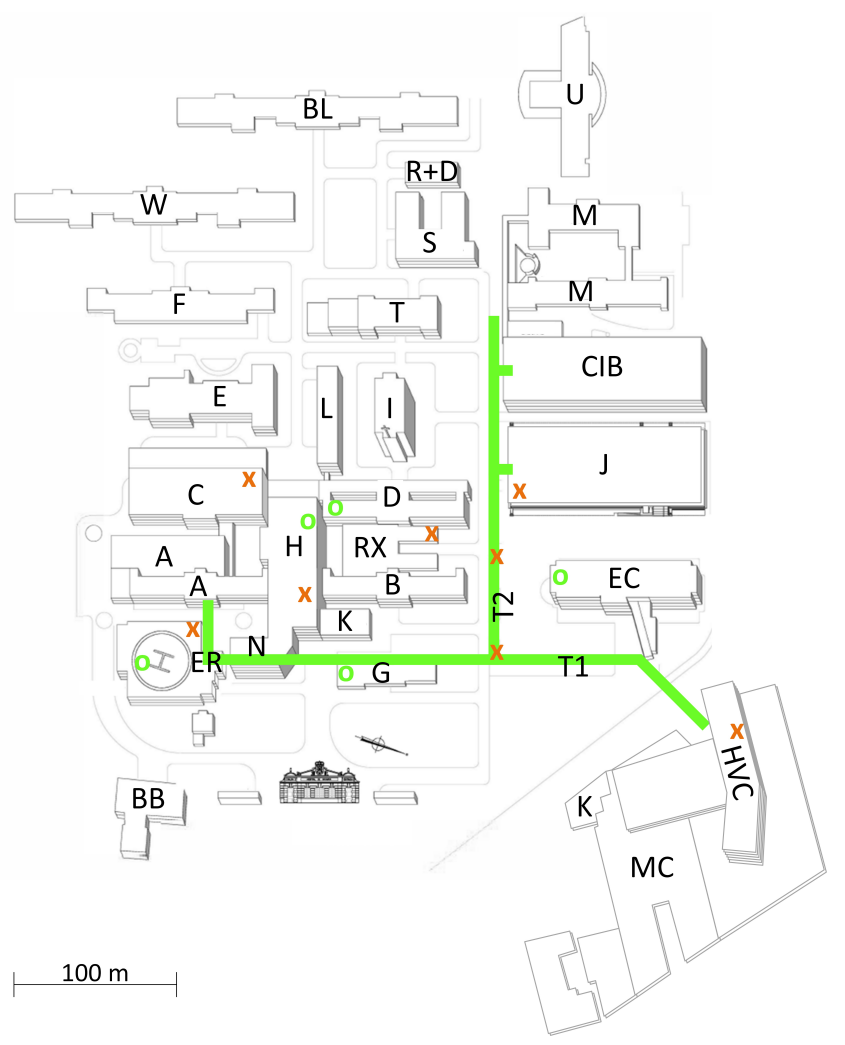

Fig. 4. Locations of the LoRa nodes ('x' marks) and gateways ('o' marks) in the HCN hospital complex. T1 and T2 tunnels are labeled as well as the names of the buildings (see Table II for further information). 


\section{2) 3D Ray Launching Simulations}

Several methodologies can be applied in order to perform wireless channel characterization and subsequent coverage/capacity analysis estimations which can be used for network design and deployment. Emprical/statistical models provide moderate accuracy (requiring in general measurement based calibration) with lower computational cost, whereas deterministic based methods can provide high accuracy with large computational cost. In order to characterize the radio channel within the hospital complex scenario, simulations by means of the in-house developed deterministic 3D Ray Launching code are performed. The algorithm is based on geometrical optics (GO) and geometrical theory of diffraction (GTD). The code has been programmed in Matlab and it has been previously used and validated in hospital environments, following a hybrid simulation approach to reduce computational cost (combining with other techniques such as neural network interpolators, electromagnetic diffusion estimation and collaborative filtering data base construction) [38]. The employed algorithm has the additional advantage of providing volumetric time domain characterization, for the complete scenario under analysis. For more detail, an exhaustive description of its operation procedure is presented in [39].

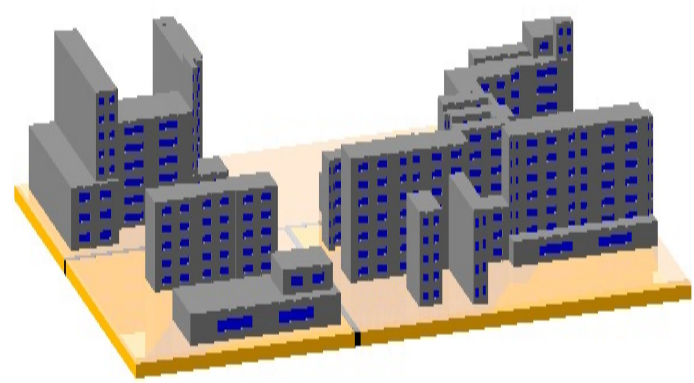

(a)

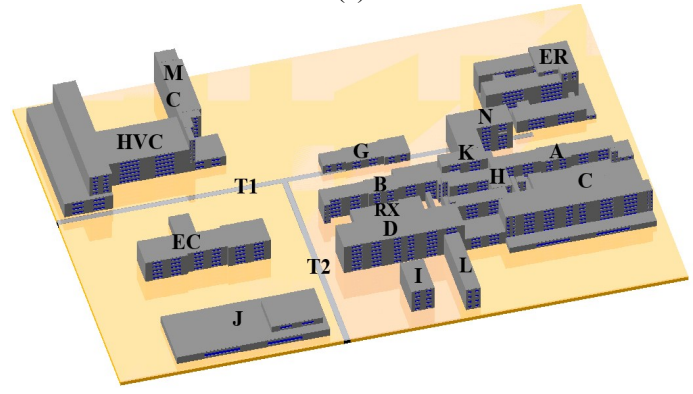

(b)

Fig. 5: HCN scenario created by the 3D Ray Launching tool: (a) General view; (b) Upper view.

In order to select the optimal locations for the LoRaWAN gateways, thus optimizing the number of the used gateways, the HCN scenario is created for simulations, as it is shown in Fig. 5. The approximate surface of the scenario is $112000 \mathrm{~m}^{2}$ and its volume is over 3.9 million $\mathrm{m}^{2}$. The scenario contains the ER, N, H, A, C, L, I, D, RX, B, K, G, J, EC, HVC and $\mathrm{MC}$ buildings. Moreover, the two main tunnels T1 and T2 are also included in the scenario. Table III presents the existing elements taken into account in terms of its effect on the radio propagation (dielectric constant and conductivity).

TABLE III

MATERIAL PROPERTIES FOR THE 3D RAY LAUNCHING ALGORITHM

\begin{tabular}{ccc}
\hline \hline \multirow{2}{*}{ Parameter } & Dielectric & Conductivity $(\sigma)[\mathrm{S} / \mathrm{m}]$ \\
\hline Constant $\left(\varepsilon_{\mathrm{r}}\right)$ & 4 & 0.12 \\
Asphalt & 5 & 0.7 \\
Glass & 6.06 & 0.11 \\
Air & 1 & 0 \\
Brick wall & 4.44 & 0.11 \\
\hline \hline
\end{tabular}

Coverage estimation provide useful information in terms of device and network design in terms of number, form factor and energy consumption. For this purpose, extensive simulations have been carried out with different gateway location within the $\mathrm{HCN}$ scenario. These locations are presented by "o" marks in Fig. 4. From the simulations results, using the gateway placed at $\mathrm{EC}$ and $\mathrm{H}$ buildings exhibit optimal results in terms of coverage levels. Power distribution at different floors levels and tunnels for the gateway placed at the EC and $\mathrm{H}$ buildings are presented in Fig. 6 and 7 respectively.

From these figures, is it shown that placing the gateway at both $\mathrm{EC}$ and $\mathrm{H}$ buildings offers radio coverage in most parts of the HCN. From Fig. 6 (b) and (c), for the gateway placed at the EC building, the estimated power levels at the targeted nodes location is the following: higher power levels at the $\mathrm{J}, \mathrm{HVC}, \mathrm{RX}$ and $\mathrm{H}$ buildings, and lower power levels in some parts and no coverage in others at the ER and $\mathrm{C}$ buildings. From Fig. 6 (d), the estimated power level at the nodes locations in tunnels is between $-60 \mathrm{dBm}$ and $-90 \mathrm{dBm}$. From Fig. 7 (b) and (c), the estimated power levels are higher at the $\mathrm{J}, \mathrm{HVC}, \mathrm{RX}, \mathrm{H}$ and $\mathrm{C}$ buildings, and lower power levels in some parts; and no coverage in others at the ER building. From Fig. 7 (d), the estimated power level at the nodes locations in tunnels is lower than $-120 \mathrm{dBm}$. It is worth noting that nominal receiver sensitivity levels are of $-148 \mathrm{dBm}$, providing feasible communication links in the case of LoRa/LoRaWan. However, for other technologies these values would be below adequate sensitivity thresholds, not achieving coverage/capacity requirements. In this case, wireless sensor network deployment would benefit from increasing node density and for specific locations, repeater solutions (complying with interference and latency requirements) can be provided.

3) Radio Coverage Measurements

The LoRaWAN nodes have been placed at the J, HVC, RX, H, C and ER building, T1 and T2 tunnels. The gateway was initially placed at the ER building and later on, it was moved to the H, D, G and EC buildings. Fig. 4 illustrates the locations of the TTN nodes and gateway and Fig. 8 presents the equipment used for measurements. In Fig. 8 (b), the gateway is affixed to a window glass on the roof of the ER building. 


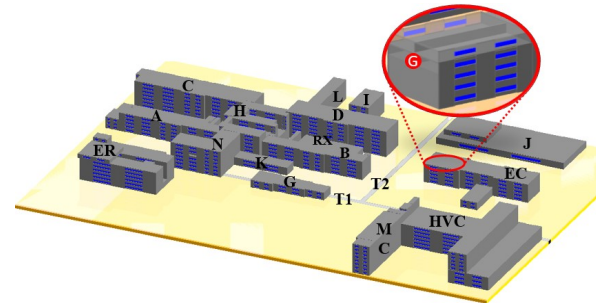

(a)

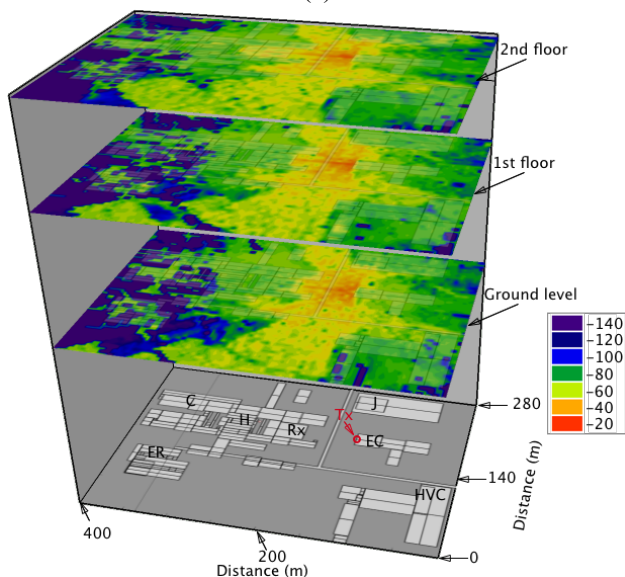

(b)

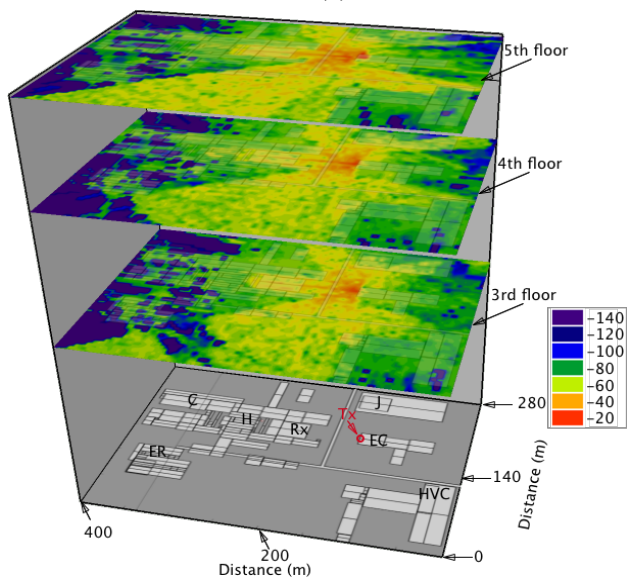

(c)

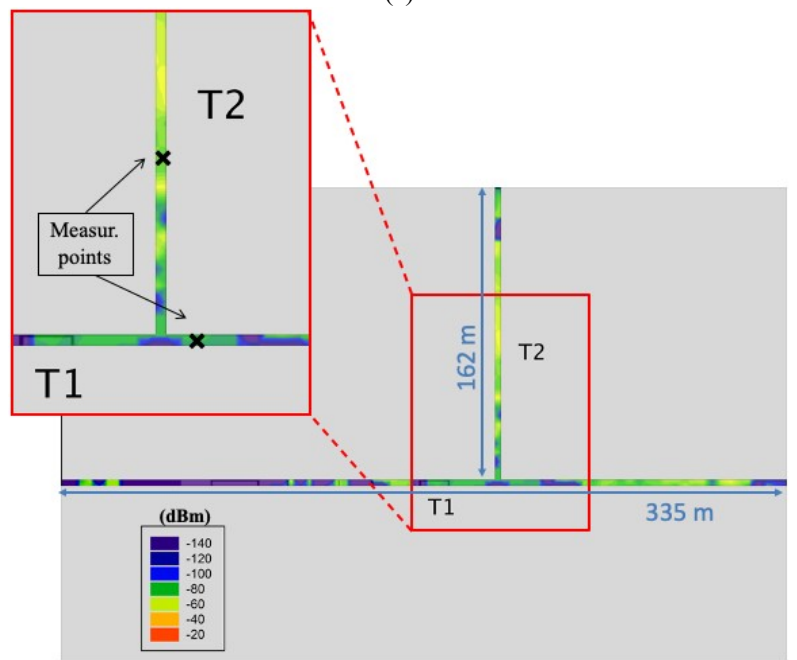

(d)

Fig. 6. (a) GW position inside the EC building. (b) and (c) Power distribution at different floors level and (d) tunnels for the gateway placed at the EC building.

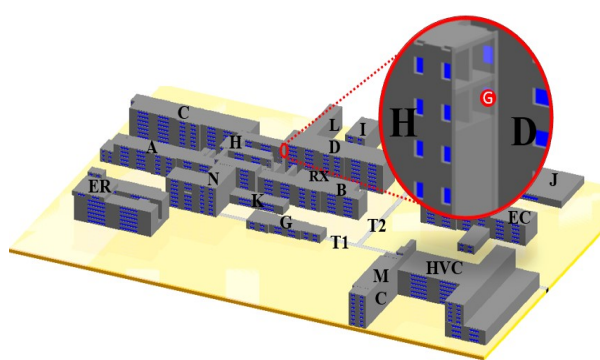

(a)

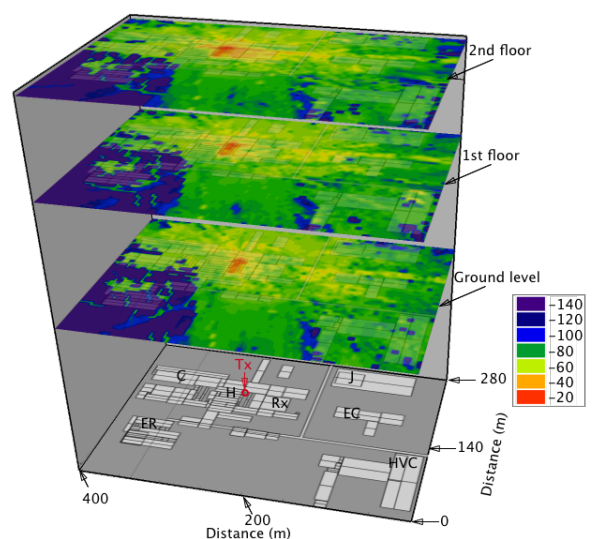

(b)

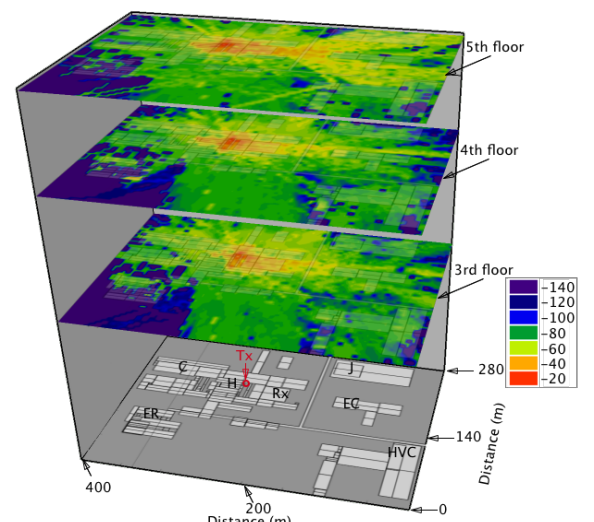

(c)

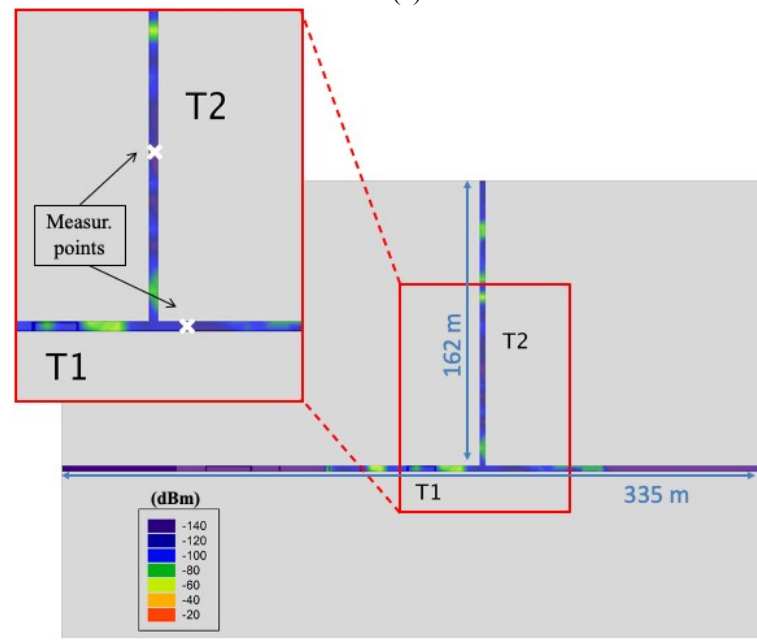

(d)

Fig. 7. (a) GW position inside the $\mathrm{H}$ building. (b) and (c) Power distribution at different floors level and (d) tunnels for the gateway placed at the $\mathrm{H}$ building. 

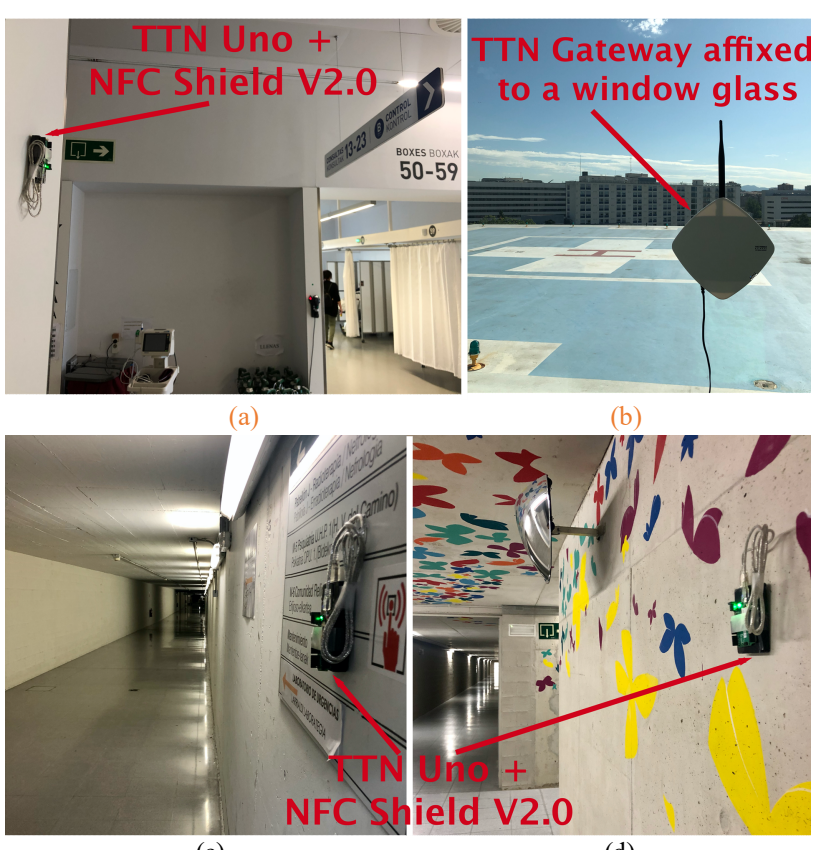

(c)

Fig. 8. LoRaWAN system deployment. Devices location at the: (a) RX building; (b) ER building; (c) Tunnel 2; (d) Tunnel 1.

Fig. 9 presents the average of measured RSSI between all nodes and gateway positions. From this figure, it is demonstrated that all gateways can communicate with the nodes placed at $\mathrm{H}$ and $\mathrm{J}$ buildings. Four out of five gateways can communicate with the RX, ER and HVC buildings. However, only the gateway placed at the $\mathrm{H}$ building can communicate with the $\mathrm{C}$ building, which is a very important one. Moreover, the gateway EC is the only one who can communicate with the main tunnels 1 and 2.

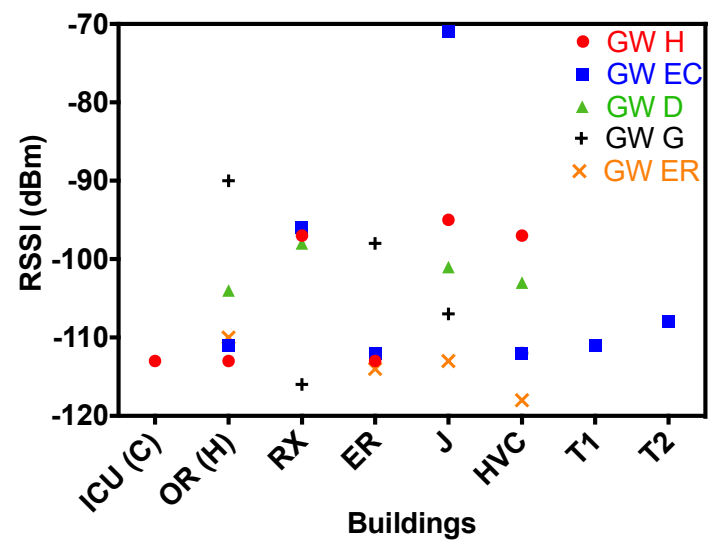

Fig. 9. Average RSSI between different gateway locations and nodes.

To facilitate the analysis, Table IV illustrates the wireless communication status between the different buildings and gateways. It is observed that the use of two gateways is sufficient to communicate with all nodes. These gateways are ones placed at the $\mathrm{H}$ and $\mathrm{EC}$ buildings. The $\mathrm{H}$ gateway is communicating with all buildings except for the tunnels, due to the big number of obstacles between them, the height difference (Gateway in the $4^{\text {nd }}$ floor and nodes under the ground) and the inherent radioelectric difficulty associated with the propagation environment itself. For the EC gateway, the communication was successful with all nodes except for the one in $\mathrm{C}$ building. This can be explained due to the multipath associated with the number of buildings in the direct vision. Moreover in the RX building, where MRIs are performed, in which operating RF fields interfere with the transmitted signals, even with EMF shielding.

TABLE IV

WIRELESS CONNECTIVITY BETWEEN DIFFERENT GATEWAYS AND NODES.

\begin{tabular}{cccccc}
\hline & GW H & GW EC & GW D & GW G & GW ER \\
\hline ICU $(\mathrm{C})$ & $\sqrt{ }$ & & & & \\
\hline OR $(\mathrm{H})$ & $\sqrt{ }$ & $\sqrt{ }$ & $\sqrt{ }$ & $\sqrt{ }$ & $\sqrt{ }$ \\
\hline RX & $\sqrt{ }$ & $\sqrt{ }$ & $\sqrt{ }$ & $\sqrt{ }$ & \\
\hline ER & $\sqrt{ }$ & $\sqrt{ }$ & & $\sqrt{ }$ & $\sqrt{ }$ \\
\hline J & $\sqrt{ }$ & $\sqrt{ }$ & $\sqrt{ }$ & $\sqrt{ }$ & $\sqrt{ }$ \\
\hline HVC & $\sqrt{ }$ & $\sqrt{ }$ & $\sqrt{ }$ & & $\sqrt{ }$ \\
\hline T1 & & $\sqrt{ }$ & & & \\
\hline T2 & $\sqrt{ }$ & & & \\
\hline
\end{tabular}

Furthermore, Fig. 10 and 11 present the received packets in terms of RSSI and SNR of the performed measurements for the gateway placed at the $\mathrm{H}$ and EC buildings. The common nodes between the $\mathrm{H}$ and $\mathrm{EC}$ gateways are OR, RX, ER, J and HVC. Both RSSI and SNR values are higher using the EC gateway in four on them (OR, RX, ER and $J$ nodes). However, the values are lower while communicating with the HVC node.

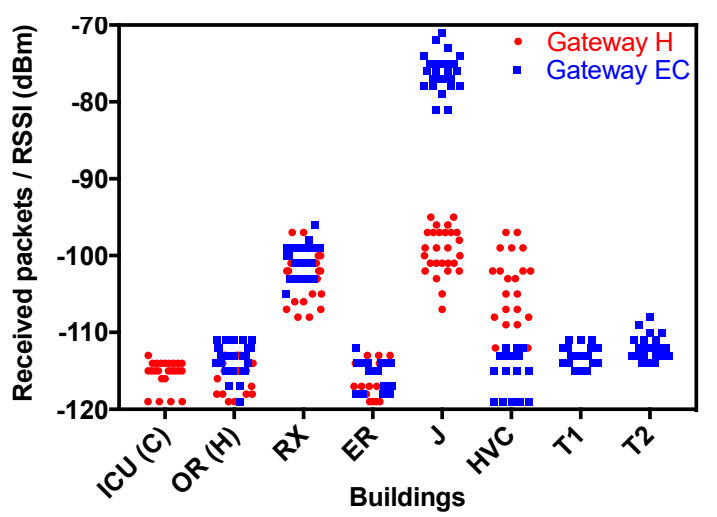

Fig. 10. Received packets in terms of RSSI between the H and EC gateways and different nodes.

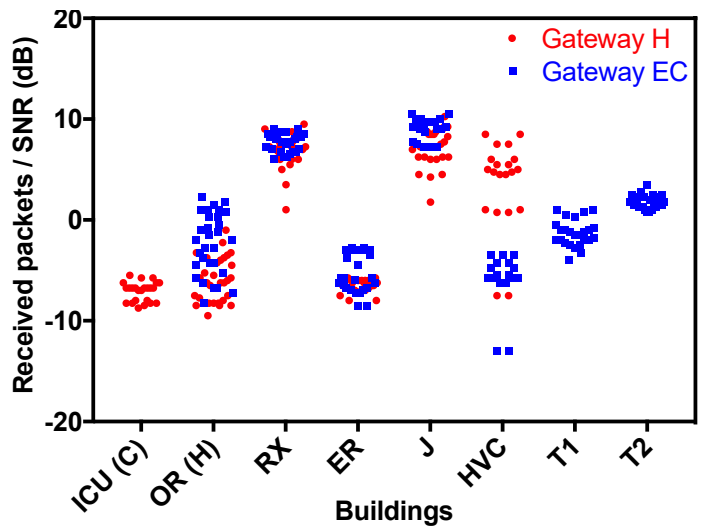

Fig. 11. Received packets in terms of RSSI between the H and EC gateways and different nodes. 
These measurements results match the 3D Ray Launching simulations results presented in Fig. 6 and 7 . The simulations predicted that placing the gateways at the $\mathrm{H}$ and EC buildings can offer the best coverage results, hence improving quality of service metrics. Moreover, the simulations anticipated the absence of communication between the $\mathrm{H}$ gateways and the two main tunnels, and the lack of communication between the EC gateway and the $\mathrm{C}$ building.

Therefore, from both simulations and measurements results, two gateways ( $\mathrm{H}$ and $\mathrm{EC}$ ) are sufficient to cover the whole hospital complex with tunnels included. Fig. 12 presents the radio coverage using both gateways within the HCN.

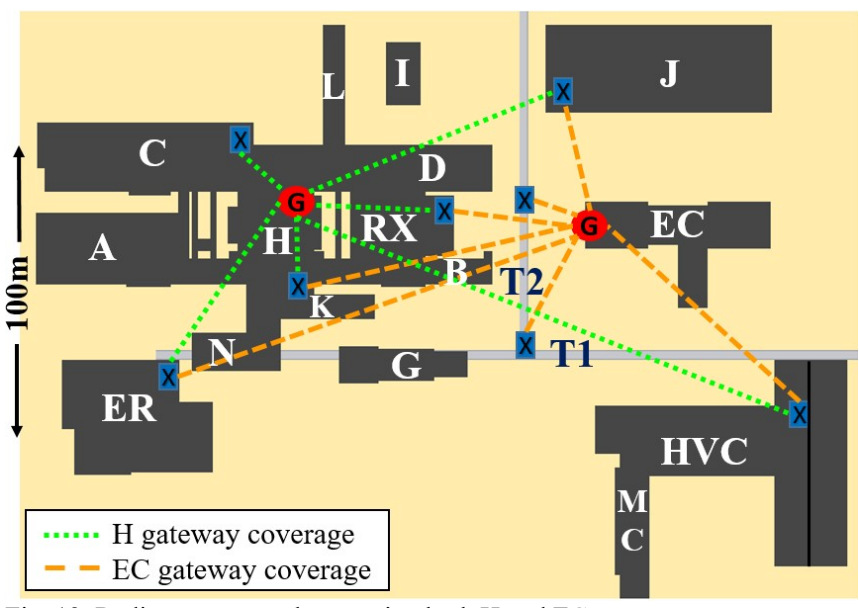

Fig. 12. Radio coverage schema using both $\mathrm{H}$ and $\mathrm{EC}$ gateways.

\section{B. Patient Tracking Application}

An Android application has been developed that enables monitoring the location and movement of users. To minimize the application's computing needs, the location and tracking processes are carried out in the cloud infrastructure and the application limits itself to adequately presenting the data provided by it. It is committed to a cloud computing strategy instead of an edge computing one in order to avoid large computational resources from the numerous corporate communication devices of healthcare personnel. The location and monitoring can be carried out on demand or with the periodicity deemed appropriate, always within the margin allowed by the frequency of location data collection, the calculation time necessary to process the information and send the location information.

The ingestion of messages in the developed cloud infrastructure is based on the open-source stream-processing tool Apache Kafka. Kafka receives the location messages provided by the devices and guarantees their adequate storage in a PostGIS database management system. The ETL Pipeline (Extract, Transform and Load) depicted in Fig 13 describes the processes of extracting data from the input data streams, transforming the data, and loading into the PostGIS storage system. PostGIS provides support for geographic objects to the PostgreSQL object-relational database. Streaming ETL allows moving real-time data from LoRa devices to an efficiently exploitable database system. In our case to the geographic information system PostGIS, which provides powerful geometry types such as Points, LineStrings, Polygons, MultiPoints, MultiLineStrings, MultiPolygons and GeometryCollections, geospatial measurements (area, length, distance, perimeter), geospatial operators (union, difference) and efficient spatial querying. This greatly facilitates the development of the Android application (ICU-Tracker). Location queries are performed over the database and with the results of these queries, the location and tracking images requested by the ICU-Tracker. Both images are offered through a web service designed ad-hoc on a smartphone as on a tablet with Android 8 operating system. A REST API provides the access to both the location service, through a GET request, and to the sending of location data from the device to the cloud, through a POST mechanism. The Kafka component includes a script which obtains the location information provided by the LoRa node, transforms the information to the geography type and loads the information into the database. Note that PostGIS v3.0 allows directly generating GeoJSON features using the $S T$ AsGeoJSON(record) function. GeoJSON is a common transport format which allows easy integration among different geoprocessing applications. Postgresol PQstGIS

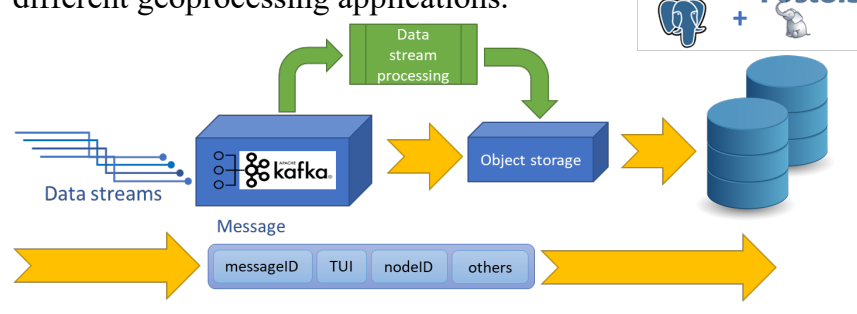

Fig. 13. ETL pipeline description.

Fig. 14 shows the appearance of the location and tracking application, which allows knowing the movement flows and the location on demand of ICU patients.

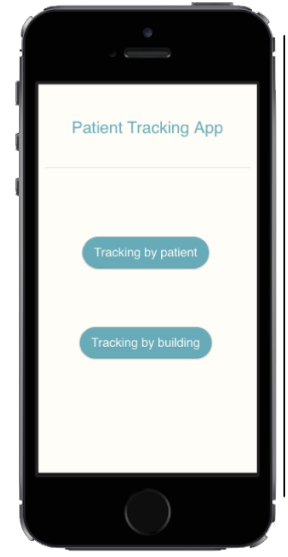

(a)

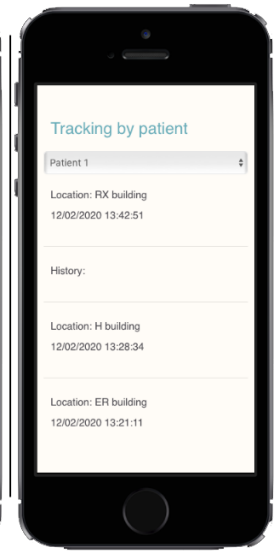

(b)

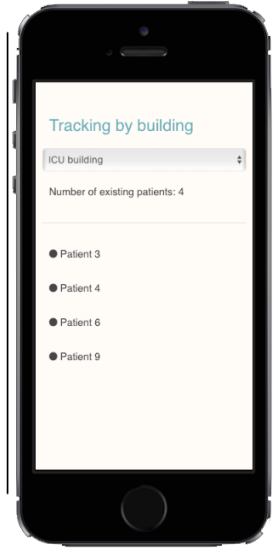

(c)
Fig. 14. Developed patient tracking application 
Depending on user's purposes, the application's menu is divided into two main sections. Tracking by patient and tracking by building, as it is shown in Fig. 14 (a). If the user's intention is to track a specific patient, then clicking on tracking by patient will take him directly to a list where he can scroll and choose the patient, (Fig. 14 (b)). When selecting the patient, information about his current location attached to the last NFC node scanning date and time will be provided. Furthermore, the location history of the patient will show up. Otherwise, if the user wants to know the patients located at a specific building, then clicking on tracking by building will give him the access to choose the required building from the buildings list. When choosing the building, a list of the located patients at the building will be provided, as it is illustrated in Fig. 14 (c).

\section{Discussion}

In this work, a LoRaWAN radio coverage studio in a multibuilding, tunnel-connected hospital complex has been carried out. The main conclusion of this analysis is that, for the use case of ICU-admitted patients, only one LoRaWAN gateway (that located in building $\mathrm{H}$ ) would be strictly necessary to cover all overground LoRaWAN nodes. If the underground nodes should be in range as well, a second LoRaWAN gateway would be required. This situation would have some advantages and drawbacks. With two gateways, the system would be more robust, since five out the eight LoRaWAN nodes would have connection to both gateways. However, the cost would be naturally increased. It is worth noting here that using the TDOA positioning technique would not be possible with just two gateways. The application of 3D RL optimized algorithm enables obtaining coverage/capacity estimations for a large and complex scenario, considering indoor/outdoor conditions, enabling thus optimal network configuration.

Leveraging the coverage studio, a secure, remote application for tracking ICU-admitted patients moving around the hospital complex has been designed and developed. The application provides the user with on-demand ICU patient movement flow around the complex. This could ultimately help in better management of resources. However, further work is necessary to analyze the economic implications as well as the usability of the system and the degree of acceptance by all stakeholders involved: patients, porters, health care professionals, and administration and management departments.

Finally, the system presented here was designed and developed for the specific use case of ICU-admitted patients at the HCN. However, the application could be scaled effortlessly to include other type of patients or even medical equipment. Moreover, the underlying idea could be extrapolated to other contexts - either medical or nonmedical.

Y.4000/Y.2060,” RyEEERENEES [Online]. Available: [1] ITU, "Overview of Internet of Things. Recommendation
https://www.itu.int/rec/dologin_pub.asp?lang=e\&id=TREC-Y.2060-201206-I!!PDF-E\&type=items.

[2] P. P. Ray, "A survey on Internet of Things architectures," Journal of King Saud University - Computer and Information Sciences, vol. 30, no. 3, pp. 291-319, Jul. 2018.

[3] A. M. Alberti, M. A. S. Santos, R. Souza, H. D. L. Silva, J. R. Carneiro, V. A. C. Figueiredo and J. J. P. C. Rodrigues, "Platforms for Smart Environments and Future Internet Design: A Survey", IEEE Access Journal, Vol. 7, no. 1, pp. 165748-165778, Dec. 2019.

[4] S. M. R. Islam, D. Kwak, M. H. Kabir, M. Hossain, and K. Kwak, "The Internet of Things for Health Care: A Comprehensive Survey," IEEE Access, vol. 3, pp. 678708, 2015.

[5] A. Ahad, M. Tahir and K. A. Yau, "5G-Based Smart Healthcare Network: Architecture, Taxonomy, Challenges and Future Research Directions," IEEE Access, vol. 7, pp. 100747-100762, 2019.

[6] Y. Zhang and H. Xiao, "Bluetooth-Based Sensor Networks for Remotely Monitoring the Physiological Signals of a Patient," IEEE Transactions on Information Technology in Biomedicine, vol. 13, no. 6, pp. 10401048, Nov. 2009.

[7] M. Neyja, S. Mumtaz, K. M. S. Huq, S. A. Busari, J. Rodriguez and Z. Zhou, "An IoT-Based E-Health Monitoring System Using ECG Signal," in GLOBECOM 2017 - 2017 IEEE Global Communications Conference, Singapore, 2017, pp. 1-6.

[8] A. H. T. E. De Silva, W. H. P. Sampath, N. H. L. Sameera, Y. W. R. Amarasinghe and A. Mitani, "Development of a wearable tele-monitoring system with IoT for bio-medical applications," in 2016 IEEE 5th Global Conference on Consumer Electronics, Kyoto, Japan, 2016, pp. 1-2.

[9] C. M. A. Carvalho, C. A. P. Rodrigues, P. A. C. Aguilar, M. F. de Castro, R. M. C. Andrade, J. Boudy, and D. Istrate, "Adaptive Tracking Model in the Framework of Medical Nursing Home Using Infrared Sensors," in 2015 IEEE Globecom Workshops (GC Wkshps), San Diego, CA, USA, 2015, pp. 1-6.

[10] J. Sie, S. Yang, Z. Hong, C. Liu, J. Chen and S. C. Li, "Integrating Cloud Computing, Internet-of-Things (IoT), and Community to Support Long-Term Care and Lost Elderly Searching," in 2016 International Computer Symposium (ICS), Chiayi, Taiwan, 2016, pp. 452-457.

[11] L. Catarinucci, D. de Donno, L. Mainetti, L. Palano, L. Patrono, M. L. Stefanizzi and L. Tarricone, "An IoTAware Architecture for Smart Healthcare Systems," IEEE Internet of Things Journal, vol. 2, no. 6, pp. 515-526, Dec. 2015.

[12] V. Varadharajan, U. Tupakula and K. Karmakar, "Secure Monitoring of Patients With Wandering Behavior in Hospital Environments," IEEE Access, vol. 6, pp. 1152311533, 2018.

[13] A. Yazdinejad, G. Srivastava, R. M. Parizi, A. Dehghantanha, K. R. Choo and M. Aledhari, "Decentralized Authentication of Distributed Patients in Hospital Networks using Blockchain," IEEE Journal of 
Biomedical and Health Informatics, to be published. 10.1109/JBHI.2020.2969648.

[14] T. Adhikary, A. D. Jana, A. Chakrabarty, and S. K. Jana, "The Internet of Things (IoT) Augmentation in Healthcare: An Application Analytics," in ICICCT 2019 - System Reliability, Quality Control, Safety, Maintenance and Management, V. K. Gunjan, V. Garcia Diaz, M. Cardona, V. K. Solanki, and K. V. N. Sunitha, Eds. Singapore: Springer Singapore, 2019, pp. 576-583.

[15] T. D. McAllister, S. El-Tawab and M. H. Heydari, "Localization of Health Center Assets Through an IoT Environment (LoCATE)," in 2017 Systems and Information Engineering Design Symposium (SIEDS), Charlottesville, VA, USA, 2017, pp. 132-137.

[16] H. K. Simpson, M. Clancy, C. Goldfrad, and K. Rowan, "Admissions to intensive care units from emergency departments: a descriptive study," Emerg Med J, vol. 22, no. 6, pp. 423-8, Jun. 2005.

[17] C. C. Braxton, P. M. Reilly, and C. W. Schwab, "The traveling intensive care unit patient: road trips," Surgical Clinics of North America, vol. 80, no. 3, pp. 949-956, Jun. 2000

[18] J. Warren, R. E. Fromm, R. A. Orr, L. C. Rotello, and H. M. Horst, "Guidelines for the inter- and intrahospital transport of critically ill patients," Critical Care Medicine, vol. 32, no. 1, pp. 256-262, Jan. 2004.

[19] P. P. Ray, D. Dash, and D. De, "A Systematic Review and Implementation of IoT-Based Pervasive SensorEnabled Tracking System for Dementia Patients," J Med Syst, vol. 43, no. 9, p. 287, Jul. 2019.

[20] F. T. Coura, R. M. d. S. Batalha, T. V. Rodrigues and N. d. F. Filho, "Matrix system for the management of resources allocation of the Intensive Care Unit (ICU) of Felicio Rocho Hospital," in 2015 IEEE Canada International Humanitarian Technology Conference (IHTC2015), Ottawa, ON, Canada, 2015, pp. 1-5.

[21] A. Redondi, M. Chirico, L. Borsani, M. Cesana and M. Tagliasacchi, "An integrated system based on wireless sensor networks for patient monitoring, localization and tracking," Ad Hoc Networks, vol. 11 (1), pp. 39-53, Jan. 2013.

[22] G. López,V. Custodio and J. I. Moreno, "LOBIN: ETextile and Wireless-Sensor-Network-Based Platform for Healthcare Monitoring in Future Hospital Environments," IEEE Transactions on Information Technology in Biomedicine, vol. 14, no. 6, pp. 1446-1458, Nov. 2010.

[23] S. Misra, J. Mahapatro, M. Mahadevappa and N. Islam, "Random room mobility model and extra-wireless body area network communication in hospital buildings," IET Networks, vol. 4, no. 1, pp. 54-64, 2015.

[24] L. Zhang, Q. Gao, X. Ma, J. Wang, T. Yang and H Wang, "DeFi: Robust Training-Free Device-Free Wireless Localization With WiFi," IEEE Transactions on Vehicular Technology, vol. 67, no. 9, pp. 8822-8831, Sept. 2018.

[25] P. A. Catherwood, S. S. Bukhari, G. Watt, W. G. Whittow and J. McLaughlin, "Body-centric wireless hospital patient monitoring networks using bodycontoured flexible antennas," IET Microwaves, Antennas \& Propagation, vol. 12, no. 2, pp. 203-210, 2018.
[26] R. Bharadwaj, S. Swaisaenyakorn, C. G. Parini, J. C. Batchelor and A. Alomainy, "Impulse Radio UltraWideband Communications for Localization and Tracking of Human Body and Limbs Movement for Healthcare Applications," IEEE Transactions on Antennas and Propagation, vol. 65, no. 12, pp. 7298-7309, Dec. 2017.

[27] Q. H. Nguyen, P. Johnson, T. T. Nguyen and M. Randles, "A novel architecture using iBeacons for localization and tracking of people within healthcare environment," in 2019 Global IoT Summit (GIoTS), Aarhus, Denmark, 2019, pp. 1-6.

[28] M. M. Alam, H. Malik, M. I. Khan, T. Pardy, A. Kuusik, and Y. L. Moullec, "A Survey on the Roles of Communication Technologies in IoT-Based Personalized Healthcare Applications," IEEE Access, vol. 6, pp. 36611-36631, 2018.

[29] U. Raza, P. Kulkarni, and M. Sooriyabandara, "Low Power Wide Area Networks: An Overview," IEEE Communications Surveys Tutorials, vol. 19, no. 2, pp. 855-873, 2017.

[30] H. Zhang, J. Li, B. Wen, Y. Xun and J. Liu, "Connecting Intelligent Things in Smart Hospitals Using NB-IoT," IEEE Internet of Things Journal, vol. 5, no. 3, pp. 1550-1560, June 2018.

[31] K. Mekki, E. Bajic, F. Chaxel, and F. Meyer, "A comparative study of LPWAN technologies for largescale IoT deployment," ICT Express, vol. 5, no. 1, pp. 17, Mar. 2019

[32] R. Henriksson, "Indoor positioning in LoRaWAN networks. Evaluation of RSS positioning in LoRaWAN networks using commercially available hardware," Master's Thesis in Communication Engineering, Chalmers University of Technology, Göteborg,Sweden, 2016.

[33] A. Yassin, Y. Nasser, M. Awad, A. Al-Dubai, R. Liu, C. Yuen, R. Raulefs, E. Aboutanios, "Recent Advances in Indoor Localization:A Survey on Theoretical Approaches and Applications", IEEE Comm Surv. Tutorials, Vol. 9, No. 2, pp. 1327-1346, 2017

[33] N. Hayati and M. Suryanegara, "The IoT LoRa system design for tracking and monitoring patient with mental disorder," in 2017 IEEE International Conference on Communication, Networks and Satellite (Comnetsat), 2017, pp. 135-139.

[34] A. T. Nugraha, N. Hayati, and M. Suryanegara, "The experimental trial of LoRa system for tracking and monitoring patient with mental disorder," in 2018 International Conference on Signals and Systems (ICSigSys), 2018, pp. 191-196.

[35] P. G. H. Metnitz et al., "SAPS 3-From evaluation of the patient to evaluation of the intensive care unit. Part 1: Objectives, methods and cohort description," Intensive Care Med, vol. 31, no. 10, pp. 1336-1344, Oct. 2005.

[36] L. P. Voigt, S. M. Pastores, N. D. Raoof, H. T. Thaler, and N. A. Halpern, "Review of A Large Clinical Series: Intrahospital Transport of Critically Ill Patients: Outcomes, Timing, and Patterns," Journal of Intensive Care Medicine, vol. 24, no. 2, pp. 108-115, Mar. 2009. 
[37] P. Lopez-Iturri, E. Aguirre, J. D. Trigo, J. J. Astrain, L. Azpilicueta, L. Serrano, J. Villadangos, and F. Falcone, "Implementation and Operational Analysis of an Interactive Intensive Care Unit within a Smart Health Context," Sensors, vol. 18, no. 2, pp. 389, 2018.

[38] L. Azpilicueta, M. Rawat, K. Rawat, F. Ghannouchi, and F. Falcone, "Convergence Analysis in Deterministic 3D Ray Launching Radio Channel Estimation in Complex Environments," ACES Journal, vol. 29, no. 4, pp. 256$271,2014$. 

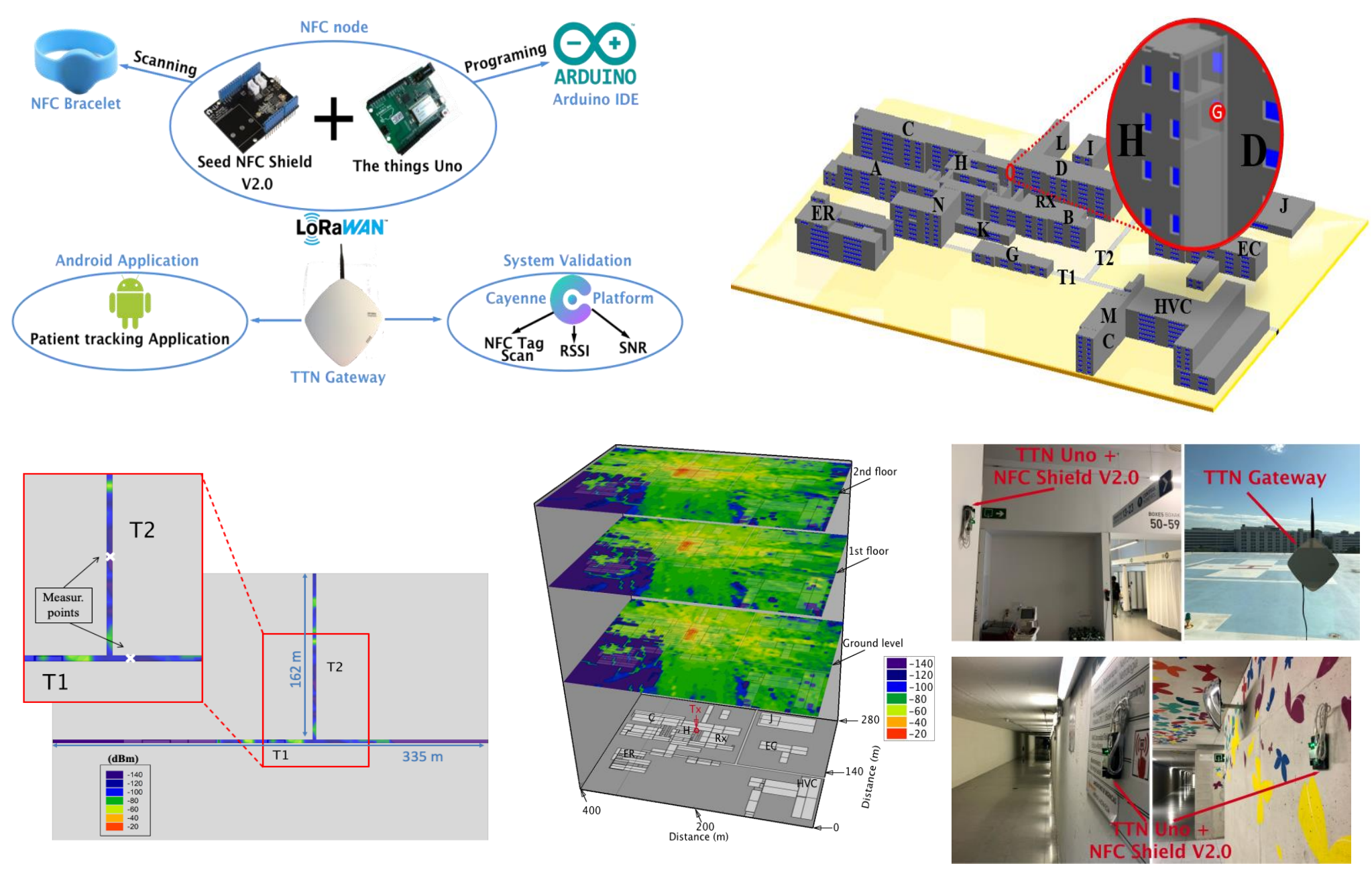